
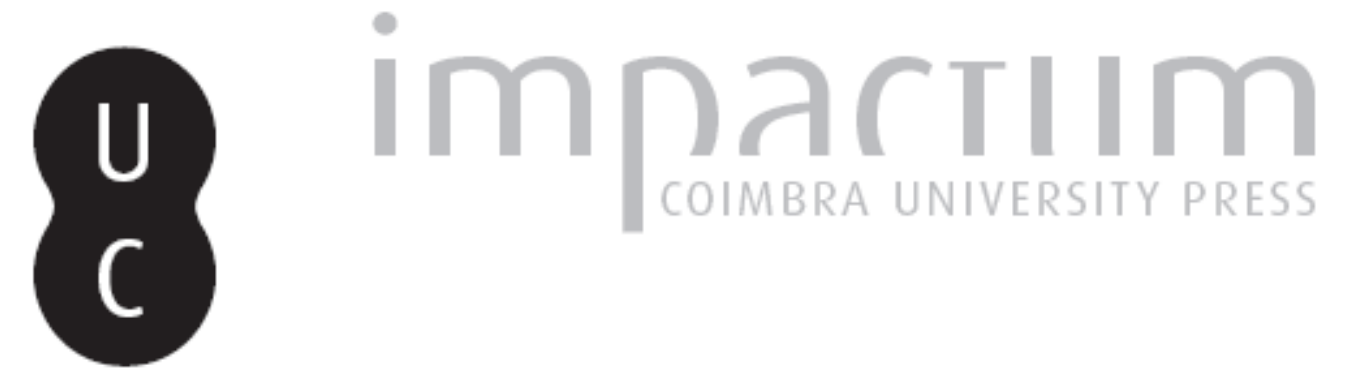

\title{
Três pequenas colecções Egípcias Particulares
}

\section{Autor(es): $\quad$ Araújo, Luís Manuel}

Publicado por: Centro de História da Universidade de Lisboa

URL persistente:

URI:http://hdl.handle.net/10316.2/23719

DOI:

DOI:http://dx.doi.org/10.14195/0871-9527_20_7

Accessed : $\quad$ 26-Apr-2023 07:02:54

A navegação consulta e descarregamento dos títulos inseridos nas Bibliotecas Digitais UC Digitalis, UC Pombalina e UC Impactum, pressupõem a aceitação plena e sem reservas dos Termos e Condições de Uso destas Bibliotecas Digitais, disponíveis em https://digitalis.uc.pt/pt-pt/termos.

Conforme exposto nos referidos Termos e Condições de Uso, o descarregamento de títulos de acesso restrito requer uma licença válida de autorização devendo o utilizador aceder ao(s) documento(s) a partir de um endereço de IP da instituição detentora da supramencionada licença.

Ao utilizador é apenas permitido o descarregamento para uso pessoal, pelo que o emprego do(s) título(s) descarregado(s) para outro fim, designadamente comercial, carece de autorização do respetivo autor ou editor da obra.

Na medida em que todas as obras da UC Digitalis se encontram protegidas pelo Código do Direito de Autor e Direitos Conexos e demais legislação aplicável, toda a cópia, parcial ou total, deste documento, nos casos em que é legalmente admitida, deverá conter ou fazer-se acompanhar por este aviso.

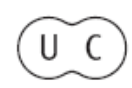




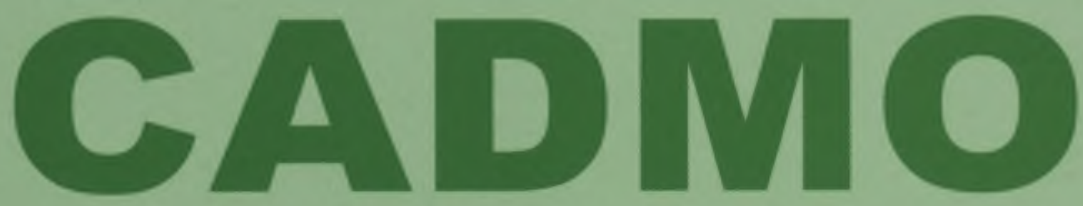

Revista de História Antiga

\author{
Centro de História \\ da Universidade de Lisboa
}

\title{
20
}

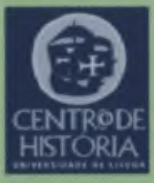

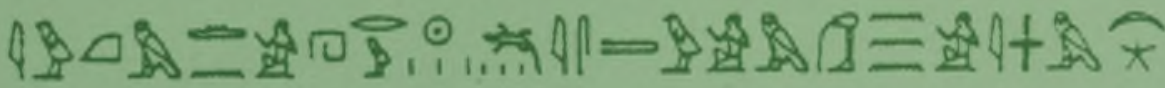

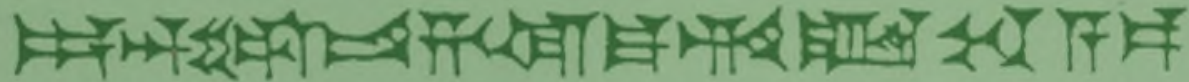

MHNIN AEI $\Delta$ E $\Theta E A ~ \Pi H \Lambda H I A \triangle E \Omega$ 


\section{TRÊS PEQUENAS COLECÇÕES EGÍPCIAS PARTICULARES}

LUÍS MANUEL DE ARAÚJO

Universidade de Lisboa

luisaraujo@fl.ul.pt

\section{Resumo}

O objectivo do artigo é divulgar os objectos pertencentes a três pequenas colecções privadas egípcias existentes em Lisboa, integrando-os no projecto mais vasto de estudo e publicação das colecções egípcias de Portugal que o Instituto Oriental vem promovendo desde há vários anos.

\section{Abstract}

The purpose of this article is to publish the objects belonging to three small private egyptian collections in Lisbon, inserting them in the wider project of study and publication of the egyptian collecions in Portugal, which the Oriental Institute has been promoting for several years.

O Instituto Oriental da Faculdade de Letras da Universidade de Lisboa, na altura dirigido pelo Professor Doutor José Nunes Carreira, abraçou em 1991 a ideia de estudar todas as colecções egípcias, públicas, privadas e particulares existentes em Portugal. Desde então, e com uma certa regularidade, tais estudos têm sido feitos, beneficiando do apoio de directores dos museus onde existem acervos egípcios e do interesse de proprietários e coleccionadores em divulgar os seus objectos. 
Até agora muitos desses estudos têm sido publicados em diversas revistas, com um especial destaque para a revista Cadmo, agora a comemorar vinte anos de existência. Para uma melhor identificação do projecto os acervos foram englobados em três grupos: as colecções de museus públicos (como é o caso do Museu Nacional de Arqueologia), as colecções de museus privados (como a do Museu Calouste Gulbenkian ou do Museu da Farmácia, este ainda em fase de constituição) e as colecções particulares (de onde se destacam, pelo número de objectos, os acervos de Miguel Barbosa e de Rui Assis Ferreira entre os quinze deste género existentes no nosso país) ${ }^{(1)}$.

$\mathrm{Na}$ sequência de anteriores artigos publicados na revista Cadmo, e também noutras revistas, aqui se apresentam três pequenos acervos privados pertencentes a coleccionadores de Lisboa. São mais sete objectos a juntar aos mais de mil que já foram divulgados, pertencentes à colecção Sá Nogueira, colecção Luís Manuel de Araújo e colecção Barahona Possolo.

\section{Colecção Sá Nogueira}

\section{1 - Boi Ápis}

Estatueta de bronze representando o boi Ápis em pose de marcha, avançando as patas esquerdas e com os cascos assentes sobre uma placa de bronze com superfície irregular. A iconografia é a habitual neste tipo de representações do touro sagrado do deus Ptah, com um disco solar entre a cornamenta. Uma serpente iaret (uraeus) com o pescoço dilatado e erguido surge à frente do disco solar, e embora com partes da superfície erodidas nota-se a pelagem do animal assinalada por incisões contínuas e pouco profundas, deixando sugerir que sobre ela e em algumas partes estariam gravados elementos habituais neste tipo de estatuetas: um manto sobre o dorso, um colar no pescoço e asas falcónidas abertas ${ }^{(2)}$.

Datação: Época Baixa ou Época Greco-Romana (664 a. C.-séc. I d. C.)

Dimensões: comp.: $5,5 \mathrm{~cm}$; alt.: $5,4 \mathrm{~cm}$ : larg.: $1,5 \mathrm{~cm}$ 


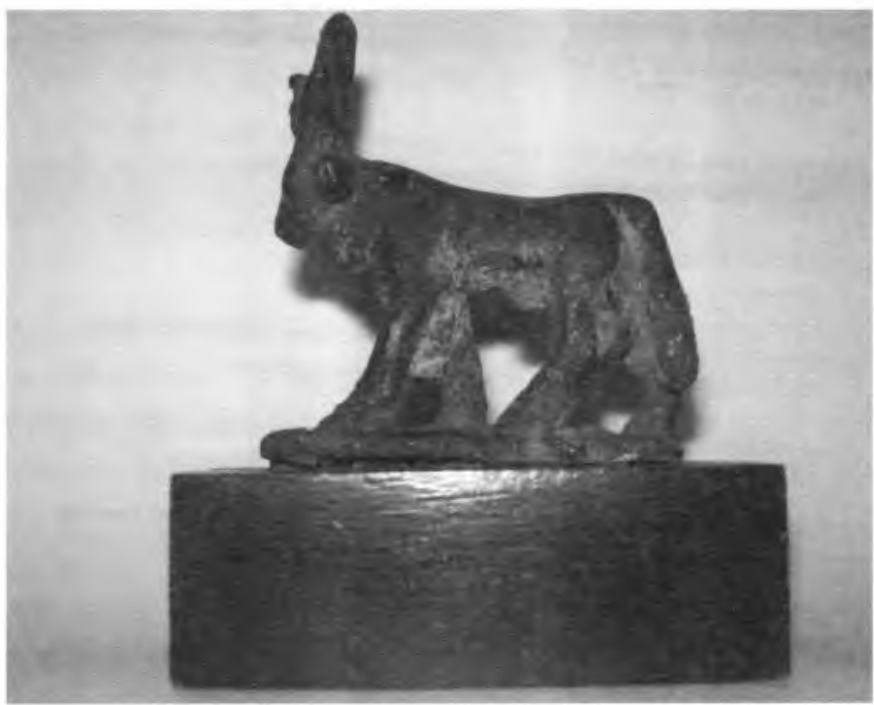

Estatueta do boi Ápis, bronze, colecção Sá Nogueira

2 - Leão

Pequeno amuleto de faiança muito erodido, representando um leão deitado em pose esfíngica, com um aro saliente para suspensão no dorso ${ }^{(3)}$.

Datação: Época Baixa (664-332 a. C.)

Dimensões: comp.: $3,5 \mathrm{~cm}$; alt.: $2 \mathrm{~cm}$

\section{Colecção Luís Manuel de Araújo}

\section{1 - Escaravelho}

Escaravelho de faiança verde com ligeiras fracturas laterais, feito de pasta vítrea homogénea de natureza siliciosa e com brilho vítreo no revestimento, mostrando a cabeça com os clípeos sumariamente marcados, protórax e élitros diferenciados por incisões, patas em relevo lateral e perfurado longitudinalmente para provável adaptação a um anel ou a um colar. Tem uma inscrição gravada na base, a qual apresenta uma orla incisa parcialmente danificada, envolvendo vários signos, podendo ler-se o nome do deus Amon e as formas bilíteras mer e neb ${ }^{(4)}$. 
Datação: Império Novo (c. 1550-1100 a. C.)

Dimensões: comp.: $2,7 \mathrm{~cm}$; larg.: $2 \mathrm{~cm}$

2 - Estatueta funerária

Estatueta funerária de faiança (uchebti) partida pela cintura, preservando a iconografia deste tipo de imagens, destinadas a trabalhar no Além em lugar do defunto. A superfície vítrea de origem já desapareceu em grande parte, subsistindo no rosto e nos ombros, e a original cor verde só se nota na face esquerda e em parte da cabeça. O suave relevo de alguns pormenores anatómicos ainda se percebe nas orelhas, sobrancelhas e olhos, nariz e boca. A pêra divina, típica das figurinhas da Época Baixa, está bem destacada entre a terminação da cabeleira tripartida que envolve o rosto arredondado. Nas mãos, que se destacam em relevo dos braços cruzados à frente, exibe os instrumentos agrícolas relacionados com os míticos trabalhos no Além: a mão direita segura um alvião e a ponta de uma corda que Ihe cai para trás sobre o ombro, e a esquerda tem um sacho ${ }^{(5)}$.

Datação: Época Baixa (c. 660-343 a. C.)

Dimensões: alt.: $4,7 \mathrm{~cm}$; larg.: $3,5 \mathrm{~cm}$

\section{Colecção Barahona Possolo}

\section{1 - Cabeça humana}

Fragmento de baixo-relevo de pedra de onde se destaca uma cabeça, aparentemente masculina, a avaliar pela análise de rostos semelhantes, embora os vestígios ténues de coloração ocre claro que ainda apresenta sugiram a típica representação da pele nas mulheres. O rosto olha para a direita e é coberto por uma cabeleira, já sem indícios de cor, que parece ser do tipo tripartido, colocada a meio da testa e quase tocando na sobrancelha bem desenhada. Abaixo está o olho bem delineado em forma amendoada e com acentuado prolongamento lateral, embora demasiado chegado à cana do nariz, que é bem proporcionado, sobrepujando uma boca de lábios de fino recorte, 
tendo o lábio superior um traço que o delimita em cima. A orelha esquerda está razoavelmente esculpida, embora o lóbulo esteja parcialmente erodido. A peça está partida pelo pescoço, deixando ainda ver o queixo arredondado(6).

Datação: Império Novo (c. 1500-1100 a. C.)

Dimensões: comp.: $20,5 \mathrm{~cm}$; alt.: $7,5 \mathrm{~cm}$; prof.: $3,2 \mathrm{~cm}$

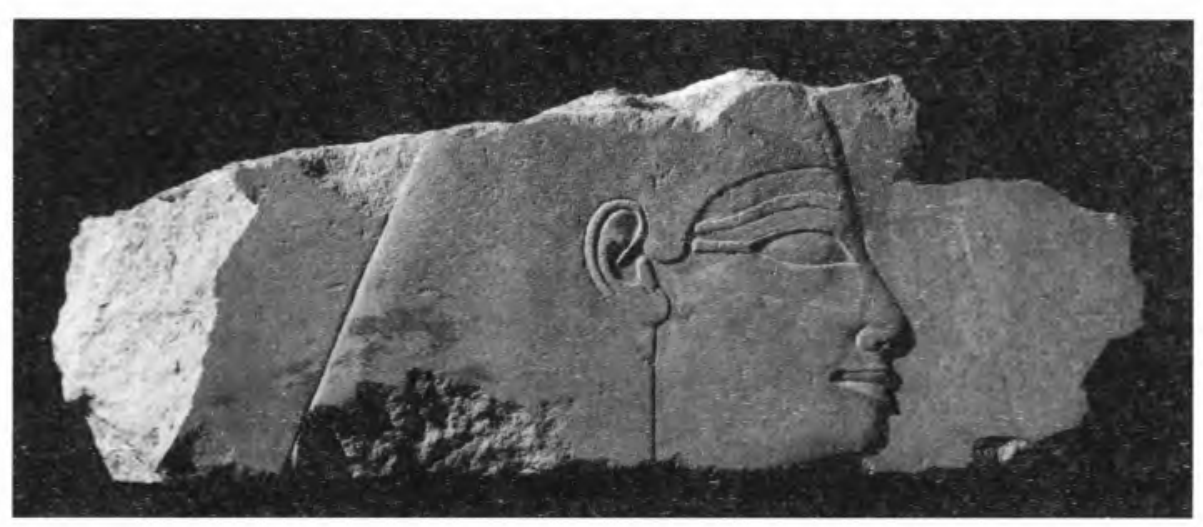

Baixo-relevo com cabeça humana

\section{2 - Escaravelho}

Pequeno escaravelho de pedra leve, aparentemente de esteatite, com a parte superior parcialmente perdida e com pequenas fracturas na orla da base em forma encartelada. Os clípeos foram feitos com cuidado, notando-se na carapaça o protórax separado dos élitros por uma incisão, estando estes também assinalados com uma incisão. As patas estão bem marcadas lateralmente em relevo e a base apresenta signos hieroglíficos que mostram duas figuras ajoelhadas frente a frente e com as mãos erguidas, tendo a da direita a coroa do Alto Egipto e a da esquerda a coroa do Baixo Egipto. Em cima parece navegar uma barca e em baixo um signo que não se consegue identificar completamente ${ }^{(7)}$.

Datação: Época Baixa (?)

Dimensões: comp.: $1,9 \mathrm{~cm}$; alt.: $1,2 \mathrm{~cm}$; larg.: $1,5 \mathrm{~cm}$ 


\section{3- Babuíno}

Estatueta de bronze representando um babuíno sentado com o corpo coberto por incisões a sugerir a pelagem do animal. Sobre a cabeça tem um disco solar com uma serpente sagrada e nas mãos exibe um papiro que se desenrola para a direita. Mostra uma expressiva anatomia da cabeça, com os olhos e as sobrancelhas, o focinho e a boca rasgada, sendo ainda de notar os detalhes dos dedos das mãos e dos pés. A figura, que assenta sobre uma base de bronze oca, à qual já falta parte da frente, evoca o animal sagrado de Tot, deus da escrita, o que justifica a presença do papiro aberto nas mãos do babuíno ${ }^{(8)}$.

Datação: Época Greco-Romana (c. 330 a. C.-séc. I d. C.) Dimensões: alt.: $20 \mathrm{~cm}$; larg.: $5,5 \mathrm{~cm}$

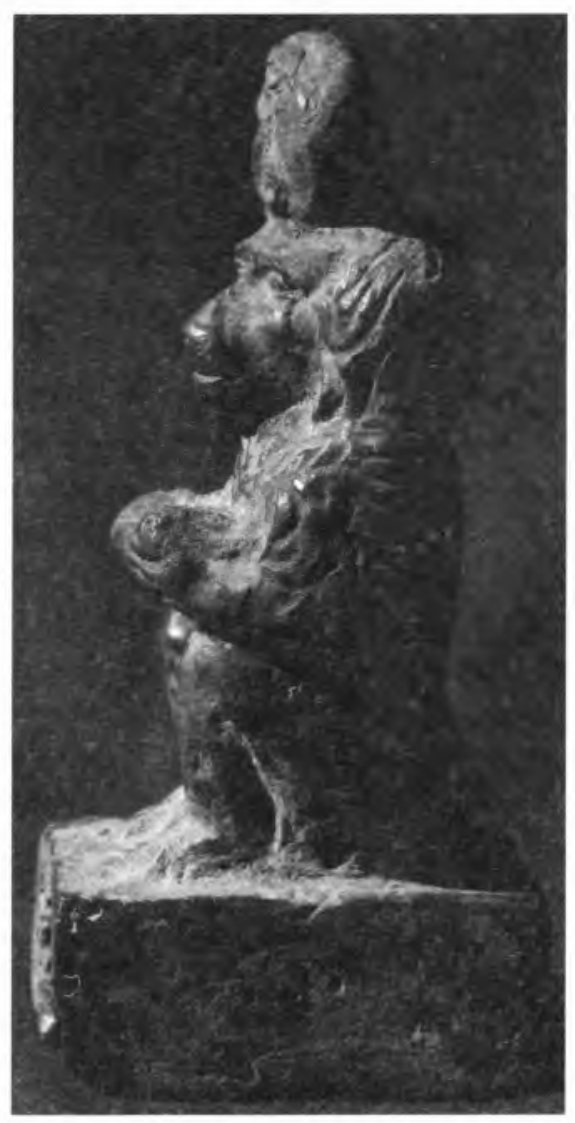

Babuíno do deus Tot 


\section{Notas}

(1) Embora os pequenos acervos particulares lisboetas divulgados no presente artigo já constassem da lista das antiguidades egípcias existentes em Portugal, os seus objectos ainda não tinham sido publicados (ver ARAÚJO, Arte Egípcia, p. 12).

(2) Não faltam estatuetas de bronze representando o boi Ápis em muitas colecções egiptológicas. Em Portugal há exemplares no Museu Nacional de Arqueologia (ver ARAÚJO, Antiguidades Egípcias, pp. 354-356), e em acervos estrangeiros foram estabelecidas comparações com imagens congéneres presentes em AFFHOLDER-GÉRARD e CORNIC, Angers, Musée Pincé, p. 52 (apesar de erodidos mostram no dorso incisões a sugerir o tradicional manto de cobertura e asas caindo sobre os flancos),

(3) A figura do leão deitado corresponde ao hieróglifo bilítero $r w$ (signo E 23 de Gardiner); ver exemplos em AFFHOLDER-GÉRARD e CORNIC, Angers, Musée Pincé, p. 140; RATIÉ, Annecy, Musée Château, p. 109.

(4) O objecto foi oferecido ao signatário pelo coleccionador Sam Levy, e esteve exposto no Museu Arqueológico de Odrinhas por ocasião da mostra sobre "O embalsamamento egípcio", feita como homenagem a Rómulo de Carvalho, de Setembro de 2007 a Março de 2008 (ver ALMEIDA e ARAÚJO, "Escaravelhos egípcios em Portugal», em Cadmo, 8, p. 118).

(5) Nas costas, onde se destaca a presença do pilar dorsal, vê-se o saco reticulado destinado a guardar as sementes. Boa variedade de modelos de uchebtis típicos da Época Baixa em SEIPEL, Ägypten. Götter, Gräber und die Kunst, pp. 220-221; exemplares do Museu Nacional de Arqueologia em ARAÚJO, Antiguidades Egípcias, pp. 222-223 (grav. 138-138); ver ainda, entre outros, AFFHOLDER-GÉRARD e CORNIC, Angers, Musée Pincé, pp. 68-69; RATIÉ, Annecy, Musée Château, pp. 102-103; KUENY e YOYOTTE, Grenoble, Musée des Beaux-Arts, pp. 72-76.

(6) A forma de representação do rosto e da pesada cabeleira a cair sobre o ombro, bem como o pormenor do olho com o prolongamento lateral e a sobrancelha espessa, são elementos iconográficos habituais durante a XVIII dinastia, e também parcialmente na XIX e XX dinastias (Império Novo, c. 1550-1100 a. C.). Ver exemplos em KUENY e YOYOTTE, Grenoble, Musée des Beaux-Arts, pp. 23-25 (neste caso trata-se de uma cabeça real, na circunstância o faraó Tutmés III, como se vê pela serpente sagrada na fronte, mas os traços gerais coincidem). Mas o tipo de representação também se detecta em rostos femininos dessa época: ver FASSONE e FERRARIS, L'Égypte. L'époque pharaonique, p. 131. Segundo informação do coleccionador, a peça foi adquirida no leilão da colecção Lucien Donnat em 20 de Dezembro de 2009, com a indicação de "Lote 294, "Fragmento Egípcio", previamente colecção de Joseph Davidson".

(7) Os inexpressivos hieróglifos que figuram na base do escaravelho podem ser o signo neb (senhor) ou o signo nub (ouro). O objecto, obtido num antiquário em Londres, trazia a seguinte identificação: "Egyptian Steatite Scarab, XVIIIth Dynasty, ca 1500. Well carved beetle in the tall style, base carved with worshipers and solar barge. Pierced for suspension $3 / 4$ "L."

(8) Ver FASSONE e FERRARIS, L'Égypte. L'époque pharaonique, p. 142. Segundo informação do coleccionador, o objecto foi adquirido há mais de 25 anos num leilão da firma "Soares e Mendonça", onde estava descrito como "macaco de bronze". 


\section{Bibliografia consultada}

Brigitte AFFHOLDER-GÉRARD e Marie-Jeanne CORNIC, Angers, Musée Pincé, Collections Égyptiennes, Inventaire des Collections Publiques Françaises, 35, Paris: Éditions de la Réunion des Musées Nationaux, 1990

Júlia Pereira de ALMEIDA e Luís Manuel de ARAÚJO, "Escaravelhos egípcios em Portugal», em Cadmo, 19, Lisboa: Centro de História da Universidade de Lisboa, 2009, pp. $97-130$

Luís Manuel de ARAÚJO, Antiguidades Egípcias, I, Museu Nacional de Arqueologia, Lisboa: Instituto Português de Museus, 1993

Luís Manuel de ARAÚJO, Arte Egípcia. Colecção Calouste Guibenkian, Lisboa: Fundação Calouste Gulbenkian, 2006

Luis Manuel de ARAÚJO, "O núcleo egípcio da colecção Sam Levy", em Artis, 1, Lisboa: Instituto de História de Arte da Faculdade de Letras de Lisboa, 2002, pp. 31-56

Alessia FASSONE e Enrico FERRARIS, L'Égypte. L'époque pharaonique, Paris: Éditions Hazan, 2008

Gabrielle KUENY e Jean YOYOTTE, Grenoble, Musée des Beaux-Arts, Inventaire des Collections Publiques Françaises, 23, Paris: Éditions de la Réunion des Musées Nationaux, 1979

Suzanne RATIÉ, Annecy, Musée Château, Chambéry, Musées d'Art et d'Histoire, Aix-lesBains, Musée Archéologique, Collections Égyptiennes, Inventaire des Collections Publiques Françaises, 28, Paris: Éditions de la Réunion des Musées Nationaux, 1984

Wilfried SEIPEL, Ägypten. Götter, Gräber und die Kunst. 4000 Jahre Jenseitsglaube, Katalog zur Ausstellung, Schlossmuseum Linz, Linz. OÖ. Landsmuseum Linz, 1989 